\title{
Coupling Coefficient Improvement and Electromagnetic Induced Noise Reduction using Short-Circuited Winding for Loosely Coupled Inductor
}

\author{
Jun Imaoka* Student Member, Willmar Martinez ${ }^{*}$ Student Member \\ Masayoshi Yamamoto* Member
}

(Manuscript received Aug. 10, 2015, revised Sep. 30, 2015)

\begin{abstract}
A loosely coupled inductor for interleaved power converters has attracted interest for downsizing magnetic components. Although the loosely coupled inductor is usually designed by adjusting the coupling coefficient in order to meet the design specifications, the coupling coefficient is saturated by the fringing fluxes in the central leg and the external leakage fluxes in the case of the EE or EI magnetic core structures. It is a matter of concern that these fluxes are causes of electromagnetic induced noise and reduction in the downsizing performance. To solve this problem, this paper proposes a short-circuited winding for the coupled inductor in order to reduce the external leakage flux in the windings. The effectiveness of the coupled inductor with a short-circuit ring is evaluated with experimental tests.
\end{abstract}

Keywords: loosely coupled inductor, external leakage flux, electromagnetic shield, short-circuited winding

\section{Introduction}

Interleaved converters with a loosely coupled inductor have attracted interest due to its high power density and low-cost of the magnetic components. However, the conventional coupled inductor that uses magnetic cores such as EE or EI shapes presents the following three problems. 1) There are external leakage fluxes in the windings, and these fluxes affect the other components as electromagnetic induced noise if the winding is located near the other components. Although there is a solution where the inductor can be arranged far from the other components, the power-density packaging is compromised. 2) Additional winding losses due to fringing flux near the air-gap occur by a long air-gap in the central leg. 3) If the coupling coefficient is saturated by these leakage fluxes, the designer has to insert an air-gap into the outer legs. However, this solution makes the mutual inductance be decreased, and the magnetizing current of transformer be increased. As a result, the power conversion efficiency may be decreased. On the other hand, the reduction in downsizing performance of the coupled inductor is also concern. This is because the leakage inductance which is proportional to the DC fluxes has to be increased when the inductor current ripple of the circuit specifications is satisfied. To solve this problem, EIE core structure, designed to suppress fringing flux, has already been proposed in ${ }^{(1)}$. However, this core structure needs three parts of magnetic cores to configure the EIE structure. In order to realize an easy manufacture, this paper proposes a Short-Circuited Winding (SCW) approach for the coupled inductor. This SCW approach is effective for reducing the external leakage flux which is one of the causes of the electromagnetic induced noise to other components. The effectiveness of this method is discussed from experimental viewpoints as well.

2. Short-circuited Winding Approach for a Loosely Coupled Inductor

The interleaved boost converter with coupled inductor is

* Shimane University

1060, Nishikawatsu, Matsue, Shimane 690-8504, Japan

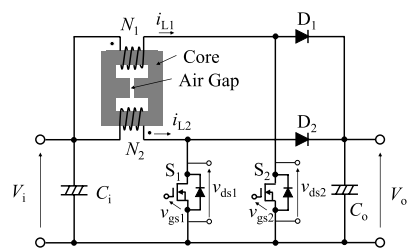

(a) Circuit configuration

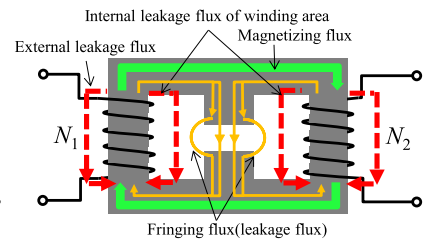

(b) Types of magnetic fluxes
Fig. 1. Interleaved converter with a loosely coupled inductor

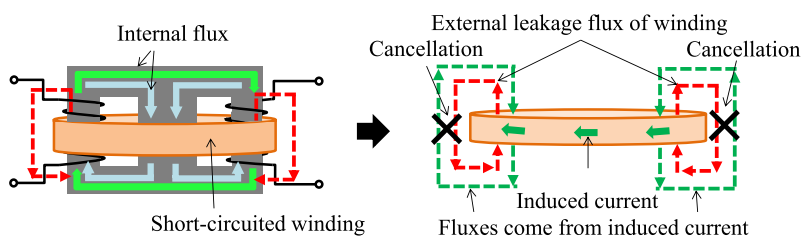

Fig. 2. Coupled inductor covered by a short-circuited winding

shown in Fig. 1(a). The magnetic core structure of the conventional loosely coupled inductor is shown in Fig. 1(b). In the coupled inductor, there are several fluxes such as the external leakage flux of the windings and the fringing flux at the air-gap and the magnetizing flux between each winding. The saturation of the coupling coefficient is caused by the fringing flux and the external leakage flux in the case of the EE core structure. As a solution method for reducing the external leakage flux, this paper proposes a coupled inductor using the $\mathrm{SCW}$. The aim of the SCW is to surround the magnetic core, see Fig. 2. The internal fluxes, including the fringing flux and the magnetizing flux, do not affect the SCW because the total interlinkage fluxes do not change. However, only the external leakage fluxes have effect inducing currents into the SCW. Therefore, the external leakage fluxes are canceled by the induced current. Consequently, the high coupling coefficient by the short-air gap length and the effect of the electromagnetic shield for the external leakage flux can be obtained.

\section{Experimental Results}

To show the effectiveness of the SCW for the coupled inductor, an experimental evaluation was carried out. The evaluation circuit parameters and the magnetic parameters are 
Table 1. Circuit parameters of the interleaved boost converter

\begin{tabular}{l|c|c}
\hline \hline Input voltage & $V_{\mathrm{i}}$ & $140 \mathrm{~V}$ \\
\hline Output voltage & $V_{\mathrm{o}}$ & $390 \mathrm{~V}$ \\
\hline Switching frequency & $f_{\mathrm{s}}$ & $100 \mathrm{kHz}$ \\
\hline Inductor ripple current & $I_{\mathrm{Lpp}}$ & $1.5 \mathrm{~A}$ \\
\hline Output power & $P_{\mathrm{o}}$ & $700 \mathrm{~W}$ \\
\hline
\end{tabular}

Table 2. Magnetic parameters

\begin{tabular}{|c|c|c|}
\hline Magnetic core & \multicolumn{2}{|c|}{ PC40EER49-Z(TDK) } \\
\hline Number of winding turns & $N$ & 44 turns \\
\hline Maximum flux density & $B_{\max }$ & $250 \mathrm{mT}$ \\
\hline \multicolumn{3}{|c|}{$\frac{1}{D \text { Designed values }}$} \\
\hline Mutual inductance & $M$ & $4.4 \mathrm{mH}$ \\
\hline Leakage inductances & $L_{\mathrm{lk} 1}, L_{\mathrm{lk} 2}$ & $138 \mu \mathrm{H}$ \\
\hline \multicolumn{3}{|c|}{ Measured values } \\
\hline \multicolumn{3}{|c|}{ Proposed loosely coupled inductor with a short circuited winding } \\
\hline Mutual inductance & $M$ & $4.5 \mathrm{mH}$ \\
\hline Leakage inductances & $L_{\mathrm{lk} 1}, L_{\mathrm{lk} 2}$ & $139 \mu \mathrm{H}, 140 \mu \mathrm{H}$ \\
\hline Air-gap length in the central leg & & $4.1 \mathrm{~mm}$ \\
\hline \multicolumn{3}{|c|}{ Conventional coupled inductor without a short circuited winding } \\
\hline Mutual inductance & $M$ & $4.5 \mathrm{mH}$ \\
\hline Leakage inductances & $L_{\mathrm{lk} 1}, L_{\mathrm{lk} 2}$ & $150 \mu \mathrm{H}, 148 \mu \mathrm{H}$ (Saturation) \\
\hline Air-gap length in the central leg & & $22.2 \mathrm{~mm}$ \\
\hline
\end{tabular}

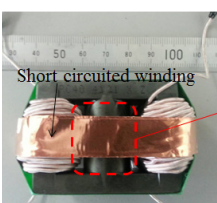

(a) with short-circuited winding

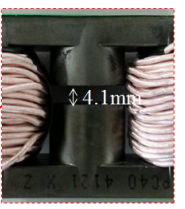

(b) without short-circuited winding
Fig. 3. Appearance of the prototypes of coupled inductor

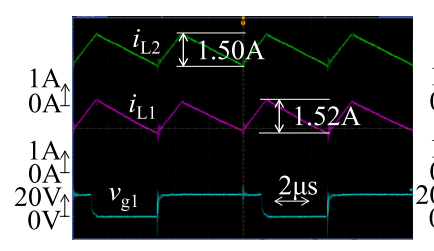

(a) with short-circuited winding

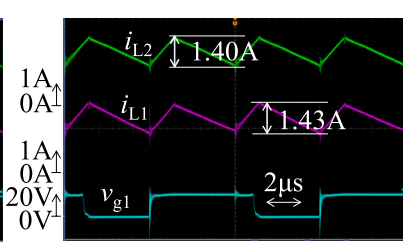

(b) without short-circuited winding
Fig. 4. Experimental waveforms

shown in Tables 1 and 2, respectively. The circuit parameters are assumed for a boost PFC converter. The inductor ripple current and the flux density are designed at $1.5 \mathrm{~A}$ and $250 \mathrm{mT}$. To obtain these designed parameters, a design method that satisfies both the inductor current ripple and the flux density is applied ${ }^{(1)}$. The design value and the measured value using the SCW and a conventional inductor are shown in Table 2. In addition, the appearances of the prototype of coupled inductors are shown in Fig. 3. As seen in this table and figure, the air-gap length of the loosely coupled inductor with SCW can be reduced in comparison with the conventional loosely coupled inductor. Therefore, this SCW approach contributes to improve the coupling coefficient. Additionally, the leakage inductance of the conventional coupled inductor is saturated around $150 \mu \mathrm{H}$. These values are different from the designed value of $140 \mu \mathrm{H}$. Therefore, the conventional loosely coupled inductor cannot obtain any leakage inductance with high mutual inductance.

Figures 4(a) and (b) show the experimental waveforms under the conditions of Table 1. From (a), (b), the proposed method fulfills the designed inductor ripple current, however the conventional coupled indcutor could not realize the design specification because of the external leakage flux. Figure 5 shows the power conversion efficiency when

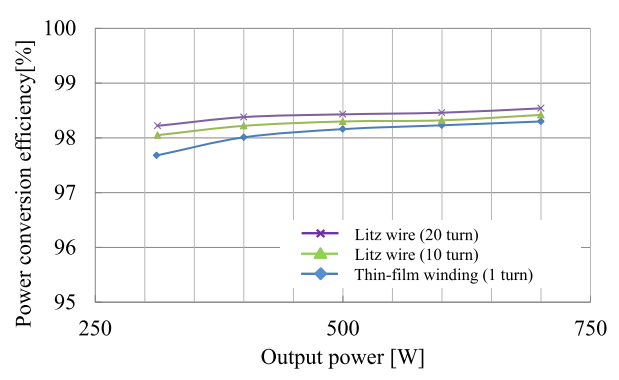

Fig. 5. Power conversion efficiency when changing short-circuited winding

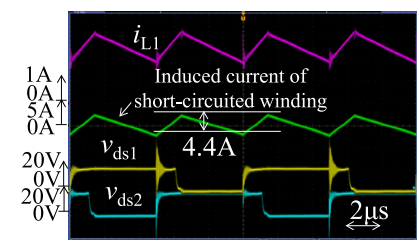

(a) Litz wire 10 turns

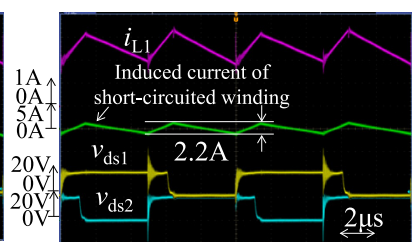

(b) Litz wire 20 turns
Fig. 6. Experimental waveforms including induced current

the structure of the SCW is changed from Litz wire to thinfilm winding. The reasons why Litz wire or thin-film winding are applied to the SCW is to reduce the AC resistance $R_{\mathrm{ac}}$ in the SCW and to improve the power conversion efficiency. From Fig. 5, the power conversion efficiency is improved if the number of winding turns for the SCW is increased. The power losses in the SCW are shown as follows:

$$
P_{\text {loss }}=R_{\text {ac }} \cdot i_{\text {ind_rms }}^{2} \cdots
$$

where $R_{\text {ac }}$ is the AC resistance of the SCW; and $i_{\text {ind_rms }}$ is the RMS value of the induced current in the SCW. By applying $\mathrm{SCW}$, the power conversion efficiency decreases due to the winding losses of the SCW. However, if the number of winding turns is increased, the induced current can be reduced as shown in Fig. 6. Therefore, the power conversion efficiency is improved in comparison with the few winding turns. If the AC resistance is close to the DC resistance of the SCW using Litz wire or thin-film winding, increment in the winding turns of the SCW is effective for realizing the improving power conversion efficiency of the converter and keeping the electromagnetic shielding effect even if $R_{\mathrm{ac}}$ is increased by the winding length.

\section{Conclusion}

This paper proposed the SCW for the loosely coupled inductor, and described some attractive features. As a future work, we will analyze the characteristic analysis of the shortcircuited winding in detailed, and we will search the effective ways to use the induced current for efficiency improvement. Furthermore, we will analyze the proposed method for high frequency applications using GaNFETs and SiC-MOSFET in order to suppress noise phenomena.

\section{Acknowledgment}

This work was partially supported by Grant-in-Aid for JSPS Fellows (No. 2611003).

\section{References}

( 1 ) J. Imaoka, et al.: "A Novel Integrated Magnetic Core Structure Suitable for Transformer-Linked Interleaved Boost Chopper Circuit", IEEJ Journal of IA, Vol.3, No.5, pp.395-404 (2014) 